\title{
A atratividade no varejo em clusters comerciais espontâneos na visão de consumidores e varejistas
}

\author{
Retail attractiveness in spontaneous commercial clusters in consumers and retailers' view
}

\author{
Marco Aurélio Sanches Fittipaldi ${ }^{a}$ \\ Orcid: https://orcid.org/0000-0002-8880-5529 \\ Denis Donaire ${ }^{b}$ \\ Orcid: https://orcid.org/0000-0002-8686-6520
}

\begin{abstract}
Resumo
O agrupamento de lojas espontâneo, cluster comercial espontâneo, tem se apresentado como tendência em grandes centros comerciais ou ruas de grande movimento. O presente estudo buscou analisar a atratividade de três clusters comerciais espontâneos de automóveis da cidade de São Paulo, por meio de uma pesquisa quantitativa descritiva, utilizando equação estrutural, com questionário estruturado a 104 consumidores e 104 varejistas, permitindo comparar as diferentes visões. Os resultados indicaram que a atratividade apresentou forte correlação entre as intenções de compra e venda nos clusters comerciais espontâneos pesquisados. Em relação ao marketing mix, verificou-se que há convergência na visão de consumidores e varejistas sobre a importância dos fatores de atratividade: apresentação, pessoal e serviços, mix de produtos e promoção. A observância desses resultados pode trazer úteis contribuições para a competição entre clusters comerciais espontâneos, que se apresentam como formas de organização cada vez mais comuns nos negócios, notadamente nos países em desenvolvimento.
\end{abstract}

Palavras-chave: atratividade. Cluster comercial. Varejo. Intenção de compra e intenção de venda.

\begin{abstract}
The grouping of stores spontaneous, spontaneous commercial cluster, has been presented as trend in large shopping centers or on busy streets. The current study aimed to analyze the attractiveness of three spontaneous commercial clusters of automobiles in the city of São Paulo, through a descriptive quantitative research carried out using structural equation, with structured questionnaire one hundred and four consumers and one hundred and two retailers, comparing the different views. The results showed that the attractiveness was presented as very strong correlation between the intention of purchasing and the selling intention spontaneous commercial clusters. In relation to the marketing mix, the results showed that there is convergence of factors such as presentation, personnel and services, product mix and promotion, in consumers and retailers' point of view. The observance of these results could bring important contributions to the competition between planned and spontaneous commercial clusters, presenting themselves as forms of organization, even more common in business.
\end{abstract}

Keywords: Attractiveness. Commercial cluster Retail. Purchasing intention. Selling intention.

\footnotetext{
${ }^{a}$ Doutor em Administração pela Universidade Municipal de São Caetano do Sul, mestre em Administração, especialista em finanças e marketing e graduado em Tecnologia de Processamento de Dados. Centro Paula Souza/FATEC - Itaquaquecetuba, São Paulo, Brasil. Email: marcoafittipaldi@yahoo.com.br

b Livre Docência em Administração pela Universidade de São Paulo (1993), Doutorado em Administração pela Universidade de São Paulo (1986), Mestrado em Administração pela Universidade de São Paulo (1979), Graduação em Ciências Econômicas e Administrativas pela Faculdade Municipal de Ciências Econômicas e Administrativas de Santo André (1967). Atualmente, atua no Programa de Mestrado e Doutorado em Administração da Universidade Municipal de São Caetano do Sul (USCS), São Paulo, Brasil. Email: denis.donaire@prof.uscs.edu.br
} 


\section{INTRODUÇÃO}

No cotidiano, por meio do boca a boca, é comum as pessoas indicarem a conhecidos e familiares ruas especializadas na comercialização de determinado produto. Em São Paulo, pode-se citar a Rua Santa Ifigênia, especializada em informática e eletrônicos, ou a Rua São Caetano, especializada em confecção e venda de artigos para noivas. Essas ruas, com aglomerações de lojas que vendem um mesmo gênero de produtos específicos, ocorrem, normalmente, em lugares com grande fluxo de pessoas e, segundo Teller e Reutterer (2008), podem constituir-se de forma espontânea ou induzida. Tal fenômeno ocorre em muitos tipos de mercados varejistas, como restaurantes, concessionárias de automóveis, instrumentos musicais, lustres entre outros (DATTA; SUDHIR, 2013) e são também conhecidos como clusters comerciais espontâneos. (ZACCARELLI, 2003).

Nota-se, nas principais cidades do país, a presença de agrupamentos varejistas de lojas, em determinadas ruas ou locais, que emergiram de forma espontânea ao longo do tempo, consolidando certa localização geográfica e que atraem grande número de consumidores (BERMAN; EVANS, 1998). Isso ocorre porque, ao se juntarem, exercem uma atração significativa aos compradores, que encontram maiores oportunidades de escolha e preços mais competitivos, ao mesmo tempo, que propiciam aos varejistas maior rentabilidade em seus negócios. $\mathrm{O}$ que não ocorre com as lojas isoladas que não contam a sinergia da existência de outras lojas para alavancar sua atratividade, requerendo maior esforço para atrair consumidores (PARENTE, 2000; LEVY E WEITZ, 2000).

O presente estudo teve por objetivo verificar os fatores da atratividade, observada nos clusters comerciais espontâneos de automóveis, segundo a visão dos consumidores e dos varejistas.

A pesquisa se justifica, do ponto de vista teórico, pela reduzida produção nacional de trabalhos relacionados à atratividade em clusters comerciais, considerando conjuntamente o ponto de vista de consumidores e varejistas. Os trabalhos estão divididos em duas vertentes: os que consideram apenas os consumidores (TELLER, 2008; TELLER; REUTERER, 2008; TELLER; ELMS, 2010; TELLER et al., 2010; TELLES et al., 2013; SIQUEIRA et al., 2015) e os que envolvem apenas os varejistas (REIMERS e CLULOW, 2004; SILVA; SILVEIRA, 2004; TELLES et al., 2011; SIQUEIRA et al., 2010; SIQUEIRA et al., 2012; TELLES et al., 2013; SIQUEIRA; LOLLO; TELLES, 2013; FITTIPALDI et al., 2013; DONAIRE et al., 2013; MARIETO; SANCHES, 2013; AGUIAR; PEREIRA; DONAIRE, 2014; GASPAR et al., 2014). Com relação ao envolvimento de consumidores e varejistas, encontra-se pouca produção (MELLO JÚNIOR, 2005; MARQUES JÚNIOR; MARTINS; MERLO, 2009; LINS; NUNES; LIMA, 2009). Assim, buscou-se neste trabalho envolver esses atores na busca de compreender os fatores de atratividade, existentes em um cluster comercial espontâneo, bem como trazer novas luzes sobre o entendimento do varejo, que é desenvolvido nos clusters comerciais espontâneos.

\section{FUNDAMENTAÇÃO TEÓRICA}

\subsection{Clusters comerciais espontâneos}

No varejo, há uma tendência das lojas se instalarem próximas umas das outras (TELLER, 2008). Esse fenômeno é, frequentemente, encontrado nas grandes cidades, são centros comerciais, situados em locais de grande concentração populacional, caracterizados pela venda de um produto específico, que emergem e têm evolução espontânea (ZACCARELLI et al., 2008, PARENTE et al., 2012). Os produtos podem ser similares ou compatíveis, comercializados ao longo de uma rua ou rodovia (BERMAN e EVANS, 1998). O agrupamento de varejistas de um mesmo ramo, como lojas de autopeças, lojas de móveis ou lojas de confecções, consegue 
distinguir essa região de outras, caracterizando-a (PARENTE, 2000).

O cluster comercial pode ser definido como um aglomerado de varejo em uma área espacial determinada (TELLER e REUTTERER, 2008; TELLER e ELMS, 2010; SIQUEIRA et al., 2010; FERREIRA; PATAH, 2018). A concentração de empresas varejistas atuantes pode ser espontânea, como ocorre em determinadas ruas comerciais (clusters comerciais espontâneos), ou intencional, como nos shopping centers (clusters comerciais planejados). Em ambos os casos, o agrupamento de lojas pode trazer benefícios e sinergia aos comerciantes (HOWELL; ROGERS, 1981; TELLER, 2008). Para os consumidores, a existência de inúmeros concorrentes em um único local diminui o risco de não encontrar o produto desejado por falta de estoque, assim como permite comparar preços. Quanto mais próximos os varejistas estiverem no cluster comercial, maior será o nível de vendas, fato que coloca os varejistas que estão fora do cluster comercial em desvantagem (OPPEWAL e HOLYOAKE, 2004).

São originados a partir de um processo de auto-organização, geralmente nas regiões centrais dos municípios e ao longo de ruas que apresentam grande fluxo de pessoas, normalmente com pouco espaço para grandes varejistas, apresentando reduzida infraestrutura de tráfego e estacionamento. Esses locais urbanos não foram planejados, concebidos e geridos como centros comerciais e apresentam grande nível de competitividade, o que faz com que sofram influências das pessoas que moram na proximidade e chamem a atenção de autoridades e políticos locais. Essa localização central pode ser considerada por alguns consumidores como um fator de atratividade, desde que proporcione boa seleção de mercadorias e serviços aos clientes, que se sentem atraídos pelas ofertas encontradas nestes locais (LEVY; WEITZ, 2000; TELLER, 2008).

A ausência de uma governança específica faz com que nessas aglomerações varejistas não haja uma estratégia para orientar seu desenvolvimento, o que acarreta uma necessidade de busca, por parte de cada lojista, de atratividade individual e não se pensa em organizar uma forma de atratividade do cluster comercial como uma entidade maior, um todo organizado de forma coletiva (TELLER, 2008).

\subsection{Atratividade}

O termo atratividade origina-se do latim da palavra attractivus e representa a qualidade do que desperta ou exerce atração. Atrativo significa exercer influência em outro, atração (BUENO, 1974). Para Ferreira (2014, p.71), atrativo significa "que tem o poder de atrair, incentivo, estímulo", podendo também ser utilizado para lugares com o significado de alguma coisa que atrai pessoas a esse lugar (CAMBRIDGE

DICTIONARIES ONLINE, 2014). Neste sentido, Nelson (1958) descreve a atração como uma força que uma aglomeração comercial exerce, baseada na disponibilidade de mercadoria, preço vantajoso, conforto físico e na conveniência.

O conceito de atração provém da psicologia social em que é vista como uma força que junta duas partes e promove, voluntariamente, uma relação. Até o final da década de 1980, o termo era citado esporadicamente em pesquisas sobre relações comerciais (MORTENSEN, 2012). A partir do início do novo século, buscou-se aprofundar sua compreensão, como demonstram os estudos de Harris, O'Malley e Patterson (2003), Ellegaard e Ritter (2007), Teller e Reutterer (2008), Teller e Elms (2010), Teller et al. (2010), e Porral e Dopico (2013).

As pesquisas sobre a natureza e os antecedentes da atratividade nos clusters comerciais, a partir da perspectiva do cliente, têm despertado a atenção de acadêmicos e profissionais de marketing de varejo (TELLER; REUTTERER, 2008). Há poucos estudos que conceituam a 
atratividade, embora se pesquise muito sobre seus resultados (HARRIS; O'MALLEY; PATTERSON, 2003; MORTENSEN, 2012).

$O$ varejista deve prestar atenção ao comportamento do consumidor para detectar quais motivos o levam à decisão de compra, assim como, desenvolver estratégias de varejo de forma a atraí-lo a consumir (TELLES et al., 2013). Nesse sentido, a atratividade pode ser definida como a convergência conjunta das intenções de compra dos consumidores e de venda dos varejistas de clusters comerciais (TELLES et al., 2013), conforme Figura 1, a seguir. Essa definição será considerada para esta pesquisa por enfocar as visões dos consumidores e dos varejistas.

Figura 1 - Atratividade em clusters comerciais

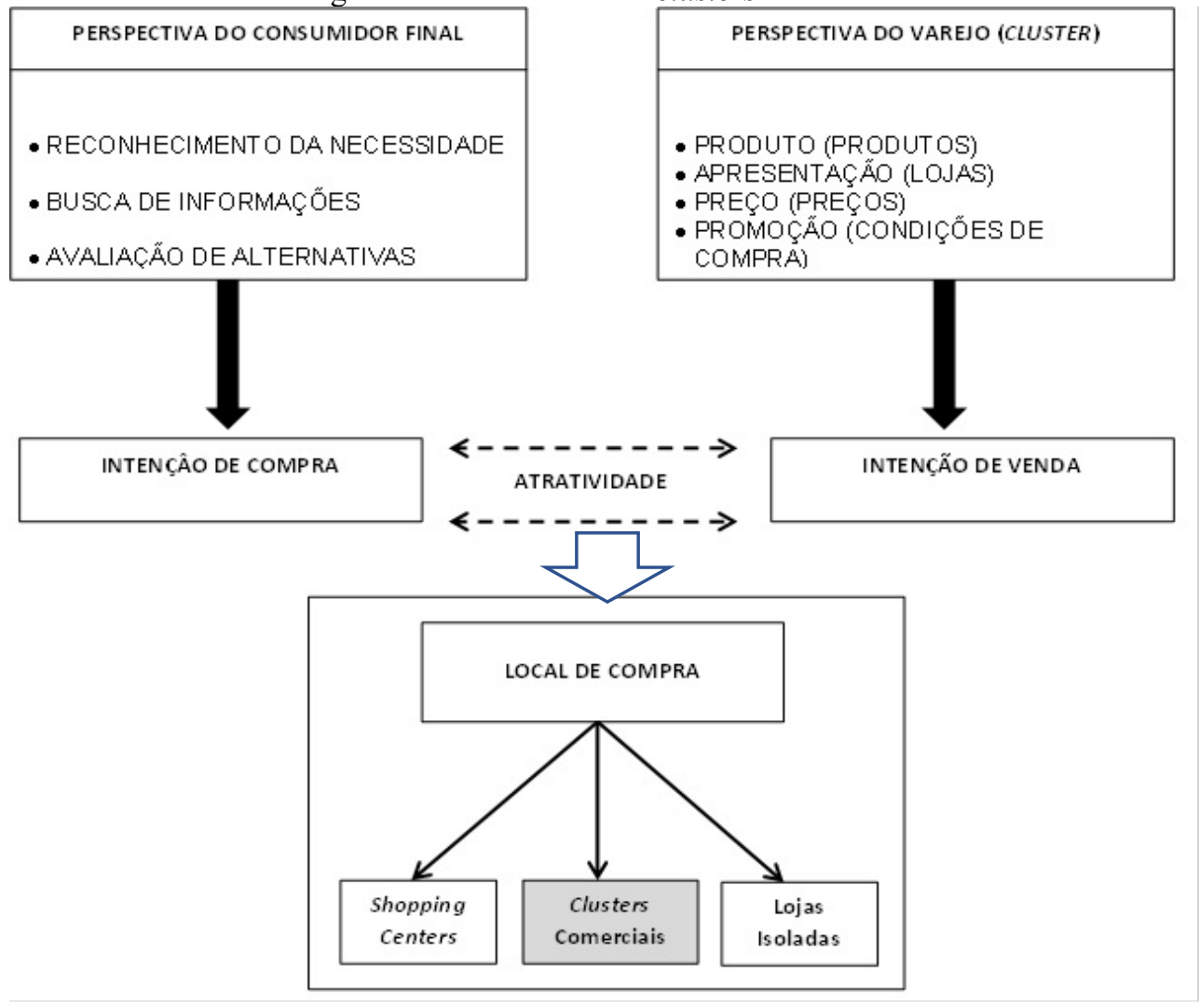

Fonte: Telles et al. (2013, p. 53)

\subsection{Proposta do Modelo a ser testado}

A revisão da literatura referente à atratividade e seus modelos conduziram à proposição de um modelo a ser testado. Partiu-se do modelo proposto por Telles et al. (2013), que considera os atributos relativos à atratividade em clusters comerciais, na visão dos consumidores, com base nas seis dimensões do mix varejista, bem como o estudo comparativo entre clusters comerciais, espontâneos e planejados, na visão dos consumidores, desenvolvido por Teller (2008).
Considerou-se, também, que consumidores e varejistas são atraídos por interesses mútuos (ELLEGAARD; RITTER, 2007), o que gera interação entre as partes envolvidas (HARRIS; O'MALLEY; PATTERSON, 2003; ELLEGAARD; RITTER, 2007). Isso faz com que o cluster comercial exerça atração nos consumidores, ideia central dos modelos gravitacionais (LEVY; WEITZ, 2000; ARANHA; FIGOLI, 2001), ou seja, como os clusters comerciais utilizam as variáveis de marketing (o mix varejista) e a resposta do consumidor a essas variações (VIGARAY; CAMINO, 1999). 
Considerou-se também que a atratividade possui um caráter dinâmico e pode ser descrita do cliente para o varejista (SCHIELE; VELDMAN; HÜTTINGER, 2010).

Desse modo, temos dois vetores, o primeiro, que leva em conta a existência de uma intenção de compra, por parte do consumidor, definida por Blackwell, Miniard e Engel (2005), e o outro, que considera a intenção de venda do varejista, entendida como o que este pensa em termos do que o consumidor deseja comprar. $\mathrm{O}$ consumidor elege os atributos que mais se destacam, conforme suas necessidades ou desejos, e o varejista deve considerar quais os atributos mais valorizados pelo comprador. Assim, entende-se a atratividade como a convergência entre estas duas intenções, como demonstrado no modelo constante na Figura 2.

Figura 2 - Modelo proposto

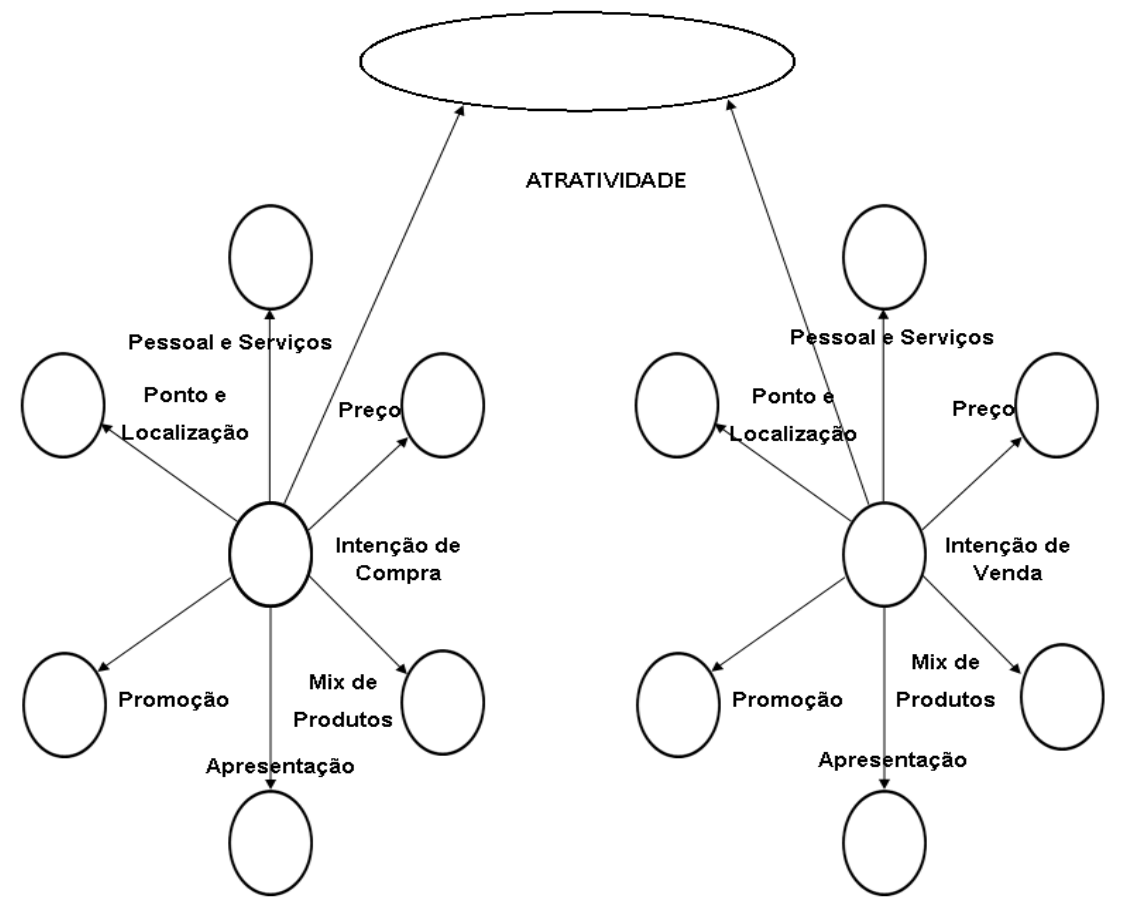

Fonte: desenvolvido pelos autores.

No modelo proposto, a intenção de venda por parte do varejo é composta pelos 6P's do mix varejista, descrito por Parente (2000), mix de produtos, apresentação, preço, promoção, pessoal e ponto e localização. Do mesmo modo, toma-se para representar a intenção de compra, por parte do consumidor, o mesmo mix varejista proposto, pois se acredita que expresse aquilo que o consumidor deseja e valoriza na relação de compra.

\section{METODOLOGIA}

Este trabalho, de cunho descritivo, descreve características da situação que envolve um problema de pesquisa (BOYD, 1978). Segundo Malhotra (2012), nesse tipo de pesquisa utiliza-se método estatístico, o que caracteriza uma pesquisa quantitativa (HAIR Jr. et al., 2005).

O objeto de estudo foi constituído por clusters comerciais espontâneos do segmento de automóveis, presentes no município de São Paulo. Foram pesquisados três clusters comerciais que comercializam automóveis: Avenida São Miguel, Avenida Marechal Tito e Avenida Professor Luís Inácio de Anhaia Melo. Foi utilizada uma amostra não probabilística (utilizando o critério de acessibilidade na seleção dos componentes da amostra). Tal fato impede 
a projeção dos resultados para a população uma vez que, os elementos escolhidos não possuem a mesma probabilidade de compor a amostra e não é possível mensurar o erro de amostragem (HAIR Jr. et al., 2005). Dessa forma, especialmente nesse caso, utilizou-se como amostra, consumidores que estavam mais disponíveis e se encontravam no local no momento da pesquisa.

Como a amostra não é probabilística, tomou-se como referência a quantidade de preditores em cada construto (pessoal e serviço, preço, mix de produtos, apresentação, promoção e ponto e localização) para o cálculo do tamanho da amostra. O construto apresentação é o que dispõe do maior número de preditores, 20. Para Hair Jr. et al. (2005), são necessários, no mínimo, 5 casos por preditor, o que para um total de 20 preditores perfaz um total de 100 casos, sendo o mínimo recomendado entre 30 a 100 casos. Como afirmam os autores, 100 casos é a quantidade recomendada para assegurar a ocorrência de resultados válidos.

Considerando que ambos os construtos (intenção de compra e intenção de venda) contêm o construto "apresentação" com 20 preditores cada, para cada cluster, deverá haver, no mínimo, a observação de 100 casos. Assim, foram entrevistados 104 consumidores e 104 varejistas nos clusters pesquisados.

Foi realizado um pré-teste, em um cluster não pertencente à amostra, com o uso da análise fatorial exploratória (AFE), para verificar a confiabilidade da escala e quais variáveis poderiam ser retiradas para ajustar o modelo. Assim, foram entrevistados 15 lojistas e 15 consumidores, perfazendo uma amostra de 30 respondentes, conforme quantidade sugerida por Malhotra (2012) para um teste inicial.

Com base nos resultados obtidos, procedeu-se a retirada das variáveis, uma por vez, para verificar quais seriam os novos valores resultantes. Essa ação se repetiu em todos os construtos, até que se chegasse a um número mínimo de variáveis que atendesse a todos os pré-requisitos da análise fatorial. De um total de 71 variáveis iniciais, foram excluídas 18 variáveis ficando um total de 53 variáveis no final do processo.

Foram desenvolvidos dois questionários diferentes, um destinado aos consumidores e um destinado aos varejistas. Para cada uma das intenções, compra e venda, foram utilizadas as seis variáveis do mix varejista. Para a mensuração dessas, foi empregada uma escala semântica bipolar de dez pontos, utilizada para mensurar atitudes (HAIR Jr. et al., 2005). Para cada variável foram construídas assertivas, as quais os entrevistados atribuíam notas que variavam de 0 (discordo totalmente) a 10 (concordo totalmente).

Em uma segunda etapa, foi realizada a análise fatorial confirmatória (AFC), aplicando-se a Modelagem de Equação Estrutural, baseada em Mínimos Quadrados Parciais (PLS-Partial Least Square), pois essa técnica busca explicar as relações existentes entre as variáveis (HAIR et al., 2009). Finalmente, para identificar a atratividade executou-se, no SPSS, a correlação entre as duas intenções (compra e venda).

Foi determinado, a priori, que o modelo testado é reflexivo, pois baseandose nas características do fenômeno, estudo da atratividade, composto pelos construtos intenção de compra e intenção de venda, notou-se que os indicadores desses construtos são manifestações próprias, ou seja, alterações nos construtos podem causar alterações nos indicadores (PREARO, 2013).

Em sequência, foram criadas as hipóteses a serem testadas, sendo seis para os consumidores e seis para os varejistas, com base na literatura consultada, conforme Figura 3. Também seguem os questionários utilizados para consumidores e varejistas, Figuras 4 e 5. 
Figura 3 - Hipóteses a serem testadas

\begin{tabular}{|c|c|}
\hline Hipóteses para os consumidores & Referencial teórico \\
\hline $\begin{array}{l}\text { H1: o mix de produto provoca um resultado } \\
\text { positivo na intenção de compra nos clusters } \\
\text { comerciais espontâneos de automóveis. }\end{array}$ & $\begin{array}{l}\text { YAVAS, 2003; THANG; TAN, 2003; MICHON et al., 2008; LUNDBERG; } \\
\text { CAMPOS; SOUZA, 2010; CHEBAT; SIRGY; GRZESKOWIAK,2010; FEIJÓ; } \\
\text { BOTELHO, 2012; CAMPOS; LUNDBERG, 2013; PORRAL; DOPICO, } 2013\end{array}$ \\
\hline $\begin{array}{l}\text { H2: a apresentação provoca um resultado } \\
\text { positivo na intenção de compra nos clusters } \\
\text { comerciais espontâneos de automóveis. }\end{array}$ & $\begin{array}{l}\text { THANG; TAN, 2003; YAVAS, 2003; LAZAROTTI et al., 2007; WAGNER, } \\
\text { 2007; LIMA, 2008; TELLER, 2008; MARQUES JUNIOR; MARTINS; } \\
\text { MERLO, 2009; TELLER; ELMS, 2010; CHEBAT; SIRGY; GRZESKOWIAK, } \\
\text { 2010; LUNDBERG; CAMPOS; SOUZA, 2010; KHARE, 2011; BANERJEE, } \\
\text { 2012; SINGH; SAHAY, 2012; PARENTE } \text { et al., } 2012\end{array}$ \\
\hline $\begin{array}{l}\text { H3: o preço provoca um resultado positivo } \\
\text { na intenção de compra nos clusters } \\
\text { comerciais espontâneos de automóveis. }\end{array}$ & $\begin{array}{l}\text { PARSONS, 2003; MELO JUNIOR, 2005; El-Adly, 2007; WAGNER, 2007; } \\
\text { LIMA, 2008; TELLER, 2008; CHEBAT, SIRGY; GRZESKOWIAK, 2010; } \\
\text { TELLER; ELMS, 2010; PORRAL; DOPICO, 2013; SILVA et al., 2014 }\end{array}$ \\
\hline $\begin{array}{l}\text { H4: a promoção provoca um resultado } \\
\text { positivo na intenção de compra nos clusters } \\
\text { comerciais espontâneos de automóveis. }\end{array}$ & $\begin{array}{l}\text { PARSONS, 2003; THANG; TAN, 2003; CHEBAT; SIRGY; GRZESKOWIAK, } \\
2010 ; \text { FEIJÓ; BOTELHO, 2012; SINGH; SAHAY, 2012; PORRAL; DOPICO, } \\
2013\end{array}$ \\
\hline $\begin{array}{l}\text { H5: pessoal e serviços provocam um } \\
\text { resultado positivo na intenção de compra nos } \\
\text { clusters comerciais espontâneos de } \\
\text { automóveis. }\end{array}$ & $\begin{array}{l}\text { BURT; CARRALERO-ENCINAS, 2000; IBRAHIM; WEE, 2002; YAVAS, } \\
\text { 2003; THANG; TAN, 2003; LAROCHE et al., 2005; El-ADLY, 2007; } \\
\text { WAGNER, 2007; MARQUES JUNIOR; MARTINS; MERLO, 2009; TELLER, } \\
\text { 2008; TELLER; ELMS, 2010; KHARE, 2011; PARENTE et al., 2012; } \\
\text { LUNDBERG; CAMPOS; SOUZA, 2012; CAMPOS; LUNDBERG, } 2013\end{array}$ \\
\hline $\begin{array}{l}\text { H6: o ponto e a localização provocam um } \\
\text { resultado positivo na intenção de compra nos } \\
\text { clusters comerciais espontâneos de } \\
\text { automóveis. }\end{array}$ & $\begin{array}{l}\text { THANG; TAN, 2003; YAVAS, 2003; MELO JUNIOR, } 2005 \text {; } \\
\text { TELLER,2008;TELLER;ELMS,2010;LUNDBERG;CAMPOS; SOUZA, 2010; } \\
\text { CHEBAT; SIRGY; GRZESKOWIAK, 2010; SINGH; SAHAY, 2012; PORRAL; } \\
\text { DOPICO, 2013; CAMPOS; LUNDBERG, } 2013\end{array}$ \\
\hline $\begin{array}{l}\text { H7: o mix de produto provoca um resultado } \\
\text { positivo na intenção de venda nos clusters } \\
\text { comerciais espontâneos de automóveis. }\end{array}$ & $\begin{array}{l}\text { DHAR; HOCH; KUMAR, 2001; SILVA; ALMEIDA, 2003; PAULA, 2008; } \\
\text { MARQUES JÚNIOR; MARTINS; MERLO, 2009; EIRA; SINEM, 2009; } \\
\text { ROODERKERK; van HEERDE; BIJMOLT, 2013; ALIPOUR-HAFEZI et al, } \\
2013\end{array}$ \\
\hline sultado & $\begin{array}{l}\text { SPINELLI; GIRALDI, 2004; PAULA, 2008; ILLANES; IKEDA, 2009; } \\
\text { SILVEIRA; SINEM, 2009; RIBEIRO et al., } 2014\end{array}$ \\
\hline $\begin{array}{l}\text { H9: o preço provoca um resultado positivo } \\
\text { na intenção de venda nos clusters comerciais } \\
\text { espontâneos de automóveis. }\end{array}$ & $\begin{array}{l}\text { DHAR; HOCH; KUMAR, 2001; SILVA; ALMEIDA, 2003; PAULA, 2008; } \\
\text { SILVEIRA; SINEM, } 2009\end{array}$ \\
\hline $\begin{array}{l}\text { H10: a promoção provoca um resultado } \\
\text { positivo na intenção de venda nos clusters } \\
\text { comerciais espontâneos de automóveis. }\end{array}$ & $\begin{array}{l}\text { DHAR; HOCH; KUMAR, 2001; BOLTON; SHANKAR, 2003; SILVEIRA; } \\
\text { SINEM, 2009; SPINELLI; GIRALDI, 2004; HEINZ; COSTA; PEREIRA, } 2014\end{array}$ \\
\hline $\begin{array}{l}\text { H11: pessoal e serviços provocam um } \\
\text { resultado positivo na intenção de venda nos } \\
\text { clusters comerciais espontâneos de } \\
\text { automóveis. }\end{array}$ & $\begin{array}{l}\text { SPINELLI; GIRALDI, 2004; PARENTE; BARKI; KATO, 2007; SILVEIRA; } \\
\text { SINEM, 2009; AKROUSH, } 2011\end{array}$ \\
\hline $\begin{array}{l}\text { H12: o ponto e a localização provocam um } \\
\text { resultado positivo na intenção de venda nos } \\
\text { clusters comerciais espontâneos de } \\
\text { automóveis. }\end{array}$ & $\begin{array}{l}\text { SILVA; ALMEIDA, 2003; SPINELLI; GIRALDI, 2004; ELIAS; CAMARGO } \\
\text { JÚNIOR, 2008; SILVEIRA; SINEM, } 2009\end{array}$ \\
\hline
\end{tabular}

Fonte: elaborado pelos autores 
Questionário 4 - Questionário consumidores

\begin{tabular}{|c|c|}
\hline Construto & Preditores \\
\hline \multirow{4}{*}{$\begin{array}{l}\text { Mix de } \\
\text { Produtos }\end{array}$} & V7-Você vem a esta rua porque encontra o produto que quer. \\
\hline & V8-Você vem a esta rua porque mesmo que não encontre o produto que quer encontra outro que lhe satisfaz. \\
\hline & V9-Você vem a esta rua porque há uma variedade maior de produtos do que nas lojas que estão fora daqui. \\
\hline & V10-Você vem a esta rua porque os produtos tem qualidade. \\
\hline \multirow{2}{*}{$\begin{array}{c}\text { Ponto e } \\
\text { localização }\end{array}$} & V11-Você vem a esta rua porque a distância não lhe impede de vir aqui \\
\hline & V12-Você vem a esta rua porque é importante encontrar em um só lugar várias lojas de carros \\
\hline \multirow{5}{*}{ Preço } & V13-Você vem a esta rua porque encontra preços mais baixos se comparado as lojas fora daqui \\
\hline & V14-Você vem a esta rua porque não percebe diferenças de preço nas lojas se comparado às lojas fora daqui \\
\hline & V15-Você vem a esta rua porque há melhores condições de financiamento \\
\hline & V16-Você vem a esta rua porque consegue melhores condições ao negociar o preço do produto escolhido \\
\hline & V17-Você vem a esta rua porque há sempre produtos com preços promocionais \\
\hline \multirow{3}{*}{ Promoção } & $\begin{array}{l}\text { V18-Você vem a esta rua porque vê muitos anúncios em revistas, televisão, internet, rádio ou jornal, se comparado as } \\
\text { lojas fora daqui }\end{array}$ \\
\hline & V19-Você vem a esta rua porque percebe mais promoções de venda aqui se comparado às lojas fora daqui \\
\hline & V20-Você vem a esta rua porque sempre promovem eventos especiais como demonstração de um novo carro \\
\hline \multirow{9}{*}{$\begin{array}{l}\text { Pessoal e } \\
\text { serviços }\end{array}$} & $\begin{array}{l}\text { V21-Você vem a esta rua porque os vendedores conhecem mais o que vendem, tem conhecimento técnico do } \\
\text { produto, o que não acontece com as lojas fora daqui }\end{array}$ \\
\hline & V22-Você vem a esta rua porque é melhor atendido aqui se comparado as lojas fora daqui \\
\hline & V23-Você vem a esta rua porque acredita que não será enganado pelos funcionários \\
\hline & V24-Você vem a esta rua porque confia nos prazos de entrega fornecidos pelas lojas \\
\hline & V25-Você vem a esta rua porque há vagas para estacionamento \\
\hline & V26-Você vem a esta rua porque o horário de funcionamento das lojas é melhor para você \\
\hline & V27-Você vem a esta rua porque o parcelamento das compras pela própria loja facilita a compra \\
\hline & V28-Você vem a esta rua porque é mais fácil efetuar devoluções ou trocas nas lojas daqui \\
\hline & V29-Você vem a esta rua porque as lojas daqui oferecem prazo de garantia estendida \\
\hline \multirow{20}{*}{$\begin{array}{l}\text { Apresentação } \\
\text { /Loja }\end{array}$} & V30-Você vem a esta rua porque encontra a loja que procura facilmente \\
\hline & V31-Você vem a esta rua porque percebe mais segurança se comparado as lojas fora daqui \\
\hline & V32-Você vem a esta rua porque as lojas são bem iluminadas (claras) \\
\hline & V33-Você vem a esta rua porque o cheiro nas lojas desta rua/shopping não lhe incomoda \\
\hline & V34-Você vem a esta rua porque se senti bem dentro das lojas, o espaço interno das lojas lhe agrada \\
\hline & V35-Você vem a esta rua porque o som nas lojas desta rua/shopping não lhe incomoda \\
\hline & V36-Você vem a esta rua porque a temperatura dentro das lojas não lhe incomoda \\
\hline & V37-Você vem a esta rua porque as lojas são limpas \\
\hline & V38-Você vem a esta rua porque as lojas e o lugar são bem conservados, o que não acontece nas lojas fora daqui \\
\hline & V39-Você vem a esta rua porque as cores nas lojas lhe agradam. \\
\hline & V40-Você vem a esta rua porque as lojas tem boa ventilação \\
\hline & V41-Você vem a esta rua porque há banheiros, o que não acontece nas lojas fora daqui \\
\hline & V42-Você vem a esta rua porque o cheiro de carro novo lhe agrada \\
\hline & V43-Você vem a esta rua porque gosta da decoração das lojas, o que não acontece nas lojas fora daqui \\
\hline & V44-Você vem a esta rua porque gosta da sinalização interna nas lojas, ajuda a se localizar mais fácil \\
\hline & $\begin{array}{l}\text { V45-Você vem a esta rua porque identifica mais facilmente as etiquetas nos produtos com preço e descrição dos } \\
\text { produtos, com isso acha mais fácil o que quer }\end{array}$ \\
\hline & V46-Você vem a esta rua porque os funcionários das lojas se vestem bem, o que não acontece nas lojas fora daqui \\
\hline & $\begin{array}{l}\text { V47-Você vem a esta rua porque os pisos são melhores, mais seguros e limpos, o que não acontece nas lojas fora } \\
\text { daqui }\end{array}$ \\
\hline & V48-Você vem a esta rua porque os produtos a venda apresentam boas condições de uso \\
\hline & V49-Você vem a esta rua porque o lugar é tão agradável que você não percebe o tempo passar. \\
\hline
\end{tabular}

Fonte: elaborado pelos autores 
Figura 5 - Questionário varejistas

\begin{tabular}{|c|c|}
\hline Construto & Preditores \\
\hline \multirow{3}{*}{$\begin{array}{c}\text { Mix de } \\
\text { Produtos }\end{array}$} & V7-O consumidor vem a esta rua porque sempre encontra o produto que quer. \\
\hline & V8-O consumidor vem a esta rua porque mesmo que não encontre o produto que quer encontra outro que lhe satisfaz. \\
\hline & V9-O consumidor vem a esta rua porque há uma variedade maior de produtos do que nas lojas que estão fora daqui. \\
\hline \multirow{3}{*}{$\begin{array}{l}\text { Ponto e } \\
\text { localização }\end{array}$} & $\begin{array}{l}\text { V10-O consumidor vem a esta rua porque a localização é de fácil acesso por carro, ônibus ou metrô, se comparado as } \\
\text { lojas fora daqui }\end{array}$ \\
\hline & V11-A distância não impede/impediria o consumidor de vir aqui \\
\hline & V12-O consumidor vem a esta rua porque encontra em um só lugar várias lojas, isto para ele é importante \\
\hline \multirow{5}{*}{ Preço } & V13-O consumidor vem a esta rua porque encontra preços mais baixos se comparado às lojas fora daqui \\
\hline & V14-O consumidor não percebe diferenças de preço nas lojas desta rua se comparado às lojas fora daqui \\
\hline & V15-O consumidor vem a esta rua porque há melhores condições de financiamento \\
\hline & V16-O consumidor vem a esta nua porque consegue melhores condições ao negociar o preço do produto escolhido \\
\hline & V17-O consumidor vem a esta rua porque há sempre produtos com preços promocionais \\
\hline \multirow{5}{*}{ Promoção } & $\begin{array}{l}\text { V18-O consumidor vem a esta rua porque vê muitos anúncios em revistas, televisão, internet, rádio ou jornal, se } \\
\text { comparado às lojas fora daqui }\end{array}$ \\
\hline & V19-O consumidor vem a esta rua porque percebe mais promoções de venda aqui se comparado às lojas fora daqui \\
\hline & $\begin{array}{l}\text { V20-O consumidor vem a esta rua porque promovem eventos especiais como: demonstração de um novo carro que } \\
\text { será lançado }\end{array}$ \\
\hline & V21-O consumidor vem a esta rua em épocas especiais como Natal ou Páscoa por causa dos sorteios que são feitos \\
\hline & $\begin{array}{l}\text { V22-O consumidor vem a esta rua porque as lojas daqui se comunicam com o consumidor sempre que há novidades } \\
\text { ou quando faz muito tempo que o consumidor não vem aqui }\end{array}$ \\
\hline \multirow{7}{*}{$\begin{array}{l}\text { Pessoal e } \\
\text { serviços }\end{array}$} & $\begin{array}{l}\text { V23-O consumidor vem a esta rua porque os vendedores conhecem mais o que vendem, tem conhecimento técnico do } \\
\text { produto, o que não acontece com as lojas fora daqui }\end{array}$ \\
\hline & V24-O consumidor vem a esta rua porque os funcionários das lojas não demoram a atendê-lo \\
\hline & V25-O consumidor vem a esta rua porque acredita que não será enganado pelos funcionários \\
\hline & V26-O consumidor vem a esta rua porque confia nos prazos de entrega fornecidos pelas lojas \\
\hline & V27-O consumidor vem a esta rua porque há vagas para estacionamento \\
\hline & V28-O consumidor vem a esta rua porque o parcelamento das compras pela própria loja facilita a compra \\
\hline & V29-O consumidor vem a esta rua porque as lojas daqui oferecem prazo de garantia estendida \\
\hline \multirow{20}{*}{$\begin{array}{l}\text { Apresentação } \\
\text { /Loja }\end{array}$} & V30-O consumidor vem a esta rua porque encontra a loja que procura facilmente \\
\hline & V31-O consumidor vem a esta rua porque percebe mais segurança se comparado às lojas fora daqui \\
\hline & V32-O consumidor vem a esta rua porque as lojas são bem iluminadas (claras) \\
\hline & V33-O consumidor vem a esta rua porque o cheiro nas lojas o agrada \\
\hline & V34-O consumidor vem a esta rua porque se senti bem dentro das lojas, o espaço interno das lojas o agrada \\
\hline & V35-O consumidor vem a esta rua porque o som dentro das lojas não o incomoda \\
\hline & V36-O consumidor vem a esta rua porque a temperatura dentro das lojas não o incomoda \\
\hline & V37-O consumidor vem a esta rua porque as lojas são limpas \\
\hline & $\begin{array}{l}\text { V38-O consumidor vem a esta rua porque as lojas e o lugar são bem conservados, o que não acontece nas lojas fora } \\
\text { daqui }\end{array}$ \\
\hline & V39-O consumidor vem a esta rua porque as cores nas lojas o agradam. \\
\hline & V40-O consumidor vem a esta rua porque as lojas tem boa ventilacão \\
\hline & V41-O consumidor vem a esta rua porque há banheiros \\
\hline & V42-O consumidor vem a esta rua porque gosta do cheiro de carro novo \\
\hline & V43-O consumidor vem a esta rua porque gosta da decoração das lojas \\
\hline & V44-O consumidor vem a esta rua porque gosta da sinalização interna nas lojas, ajuda a se localizar mais fácil na loja \\
\hline & $\begin{array}{l}\text { V45-O consumidor vem a esta rua porque identifica mais facilmente etiquetas dos produtos com preço e descrição } \\
\text { dos produtos, com isso acha mais fácil o que quer }\end{array}$ \\
\hline & $\begin{array}{l}\text { V46-O consumidor vem a esta rua porque os funcionários das lojas se vestem bem, o que não acontece nas lojas fora } \\
\text { daqui }\end{array}$ \\
\hline & $\begin{array}{l}\text { V47-O consumidor vem a esta rua porque os pisos são melhores, mais seguros e limpos, o que não acontece nas lojas } \\
\text { fora daqui }\end{array}$ \\
\hline & V48-O consumidor vem a esta rua porque os produtos a venda apresentam boas condições de uso \\
\hline & vem a esta rua porque o lugar é tão agradável que não percebe o tempo passar. \\
\hline
\end{tabular}

Fonte: elaborado pelos autores

\section{ANÁLISE DOS RESULTADOS}

Os locais pesquisados, três avenidas que comercializam automóveis, caracterizam-se pela grande concentração de varejo (LEVY e WEITZ, 2000; MATTAR, 2011), a aglomeração

possui características próprias que não existem em empresas que operam isoladamente (ZACCARELLI et al., 2008). Isso gera uma intensa competição interna 
entre os varejistas (PE'ER e KEIL, 2013), mas também torna-os mais atrativos para os consumidores

(OPPEWAL

HOLYOAKE, 2004; SIQUEIRA et al., 2010; FERREIRA; PATAH, 2018), criando-se vantagem competitiva. Assim configuram-se os locais da pesquisa como clusters comerciais (TELLER e REUTTERER, 2008; TELLER e ELMS, 2010; SIQUEIRA et al., 2010; SIQUEIRA et al., 2012; PARENTE et al., 2012; SIQUEIRA, LOLLO e TELLES, 2013; AGUIAR, PEREIRA e DONAIRE, 2014). Os clusters comerciais são classificados como espontâneos devido à falta de organização para sua formação (TELLER, 2008; TELLER e ELMS, 2010). Em sequência são analisados os resultados do modelo aplicado a consumidores e varejistas.

\subsection{Consumidores dos clusters comerciais espontâneos}

Inicialmente, analisa-se a validade convergente dos construtos (AVE), representada pela variância dos indicadores, capturada pelo construto em relação à variância total (PREARO, 2013; RINGLE; SILVA; BIDO, 2014). Foram utilizados, como critério, valores de AVE maiores que 0,50 (PREARO, 2013; RINGLE; SILVA; BIDO, 2014). A Tabela 1 demonstra os valores da validade convergente e da confiabilidade composta.

\begin{tabular}{|c|c|c|}
\hline & AVE & $\begin{array}{l}\text { Composite } \\
\text { Reliability }\end{array}$ \\
\hline Apresentação & 0,635 & 0,972 \\
\hline Intenção de Compra & 0,508 & 0,977 \\
\hline Mix de Produtos & 0,652 & 0,882 \\
\hline Pessoal e Serviços & 0,558 & 0,919 \\
\hline Ponto e Localização & 0,734 & 0,847 \\
\hline Preço & 0,717 & 0,910 \\
\hline Promoção & 0,750 & 0,900 \\
\hline
\end{tabular}

Nota-se na Tabela 1, que todos os construtos apresentam valores acima de 0,50 na validade convergente dos construtos, o que satisfaz ao critério prédeterminado (PREARO, 2013; RINGLE; SILVA; BIDO, 2014). Com relação à confiabilidade composta, nota-se que todos os construtos apresentam valores maiores que 0,70 . Isto significa que os indicadores dos construtos são altamente confiáveis e intercorrelacionados, "indicando que eles todos parecem medir a mesma coisa" (HAIR Jr. et al., 2009, p. 540).

A validade discriminante, segundo o critério de Fornell-Larcker, determina que "a variável latente compartilha mais variância com seus indicadores do que com qualquer outra variável latente" (HENSELER; RINGLE; SINKOVICS, 2009, p. 299). Os dados constam na Tabela 2. 
Tabela 2 Validade discriminante - Fornell-Larcker

\begin{tabular}{l|r|l|l|l|l|r}
\hline & \multicolumn{1}{|l|}{ Apresentação } & $\begin{array}{l}\text { Mix de } \\
\text { Produtos }\end{array}$ & $\begin{array}{l}\text { Pessoal e } \\
\text { Serviços }\end{array}$ & $\begin{array}{l}\text { Ponto e } \\
\text { Localização }\end{array}$ & Preço & Promoção \\
\hline Apresentação & 0,797 & & & & & \\
\hline Mix de Produtos & 0,738 & 0,808 & & & & \\
\hline $\begin{array}{l}\text { Pessoal e } \\
\text { Serviços }\end{array}$ & 0,780 & 0,689 & 0,845 & & & \\
\hline $\begin{array}{l}\text { Ponto e } \\
\text { Localização }\end{array}$ & 0,736 & 0,725 & 0,659 & 0,857 & & \\
\hline Preço & 0,641 & 0,667 & 0,662 & 0,478 & 0,846 & \\
\hline Promoção & 0,573 & 0,495 & 0,635 & 0,353 & 0,613 & 0,865 \\
\hline
\end{tabular}

Fonte: Dados extraídos do software Smart PLS.

Como pode ser notada na Tabela 2 , a diagonal principal indica os valores da variância extraída de cada construto. Notase que tais valores são maiores que o quadrado da correlação entre o construto e qualquer outro construto (HENSELER; RINGLE; SINKOVICS, 2009; PREARO, 2013). A validade discriminante diferencia os construtos, ou seja, "itens individuais medidos devem representar somente um construto latente" (HAIR Jr. et al., 2009, p. 593). Assim, verifica-se a existência de validade discriminante.

A próxima análise refere-se à qualidade do modelo ajustado, representada pelos coeficientes de determinação de Pearson ( $\left.\mathrm{R}^{2}\right)$ (RINGLE; SILVA; BIDO, 2014). Esses podem ser notados na Tabela 3 , a seguir.

Tabela 3 Coeficientes de determinação de Pearson $\left(\mathrm{R}^{2}\right)$

\begin{tabular}{|c|c|}
\hline & $\begin{array}{c}\text { R } \\
\text { Square }\end{array}$ \\
\hline Apresentação & 0,942 \\
\hline Mix de Produtos & 0,685 \\
\hline Pessoal e Serviços & 0,748 \\
\hline Ponto e Localização & 0,596 \\
\hline Preço & 0,578 \\
\hline Promoção & 0,451 \\
\hline
\end{tabular}

Fonte: Dados extraídos do software Smart PLS.

A análise da Tabela 3 permite afirmar que os indicadores explicam $94,2 \%$ do construto apresentação, 74,8\% do construto pessoal e serviços, e $68,5 \%$ do construto mix de produtos, todos considerados com explicação substancial. Os indicadores explicam, respectivamente, $59,6 \%$ do construto ponto e localização, $57,8 \%$ do construto preço e $45,1 \%$ do construto promoção, todos considerados de explicação moderada (CHIN, 1998 apud PREARO, 2013).

O teste de significância das relações, representado por bootstrapping - técnica de reamostragem (RINGLE; SILVA; BIDO,
2014), faz a validação de um modelo multivariado por meio de uma grande quantidade de subamostras (HAIR Jr. et al., 2009). Verifica a significância estatística de cada coeficiente estrutural por meio do teste t de Student, sendo que valores maiores que 1,96 são considerados estatisticamente significantes com valores de $p \leq 0,05$. Os valores do teste $t$ das relações entre os construtos com seus respectivos indicadores encontram-se acima de 1,96; assim como os valores do teste $t$ entre os construtos com intenção de compra também são superiores a 1,96 (HAIR Jr. et al., 2009; PREARO, 2013; RINGLE; SILVA; BIDO, 2014). 
A Tabela 4 mostra os valores de $p$ inferiores a 0,05 , o que significa que as cargas fatoriais e os coeficientes de regressão são significantes (RINGLE;
SILVA; BIDO, 2014). Com isso, pode-se aceitar todas as hipóteses propostas referentes aos consumidores de clusters comerciais espontâneos, conforme Figura 6.

Tabela $4 p$ values

\begin{tabular}{l|l}
\hline & $p$ values \\
\hline INTENÇÃO DE COMPRA $>$ APRESENTAÇÃOO & $<0,05$ \\
\hline INTENÇÃOO DE COMPRA $>$ MIX DE PRODUTOS & $<0,05$ \\
\hline INTENÇÃOO DE COMPRA $>$ PESSOAL E SERVIÇOS & $<0,05$ \\
\hline INTENÇÃ̃O DE COMPRA $>$ PONTO E LOCALIZAÇÃO & $<0,05$ \\
\hline INTENÇÃO DE COMPRA $>$ PREÇO & $<0,05$ \\
\hline INTENÇÃOO DE COMPRA $>$ PROMOÇÃO & $<0,05$ \\
\hline
\end{tabular}

Fonte: Dados extraídos do software Smart PLS.

Figura 6 - Hipóteses consumidores

\begin{tabular}{|c|c|}
\hline ses & \\
\hline $\begin{array}{l}\text { H1: o mix de produto provoca um resultado positivo na } \\
\text { intenção de compra nos clusters comerciais espontâneos de } \\
\text { automóveis }\end{array}$ & Confirmada \\
\hline $\begin{array}{l}\text { H2: a apresentação provoca um resultado positivo na intenção } \\
\text { de compra nos clusters comerciais espontâneos de } \\
\text { automóveis. }\end{array}$ & Confirmada \\
\hline $\begin{array}{l}\text { H3 o preço provoca um resultado positivo na intenção de } \\
\text { compra nos clusters comerciais espontâneos de automóveis }\end{array}$ & Confirmada \\
\hline $\begin{array}{l}\text { H4: a promoção provoca um resultado positivo na intenção de } \\
\text { compra nos clusters comerciais espontâneos de automóveis }\end{array}$ & Confirmada \\
\hline $\begin{array}{l}\text { H5: pessoal e serviços provocam um resultado positivo na } \\
\text { intenção de compra nos clusters comerciais espontâneos de } \\
\text { automóveis }\end{array}$ & Confirmada \\
\hline $\begin{array}{l}\text { H6: o ponto e a localização provocam um resultado positivo na } \\
\text { intenção de compra nos clusters comerciais espontâneos de } \\
\text { automóveis }\end{array}$ & Confirmada \\
\hline
\end{tabular}

Fonte: elaborado pelos autores.

Os indicadores de qualidade de ajuste do modelo, representados pela relevância ou validade preditiva $\left(\mathrm{Q}^{2}\right)$ ou indicador de Stone-Geisser e pelo tamanho do efeito $\left(\mathrm{f}^{2}\right)$ ou indicador de Cohen (RINGLE; SILVA; BIDO, 2014), estão representados na Tabela 5.

Tabela 5 Indicadores de Stone-Geisser e Cohen

\begin{tabular}{l|c|c}
\hline \multicolumn{1}{c|}{ Construtos } & $\mathbf{Q}^{2}$ & $\mathbf{f}^{2}$ \\
\hline Pessoal e Serviços & 0,517 & 0,521 \\
\hline Mix de Produtos & 0,440 & 0,413 \\
\hline Ponto e Localização & 0,423 & 0,201 \\
\hline Apresentação & 0,587 & 0,585 \\
\hline Preço & 0,402 & 0,519 \\
\hline Promoção & 0,299 & 0,479 \\
\hline
\end{tabular}

Fonte: Dados extraídos do software Smart PLS. 
A validade preditiva $\left(\mathrm{Q}^{2}\right)$ mede "quanto o modelo se aproxima do que se espera dele" (ou a qualidade da predição do modelo ou acurácia do modelo ajustado) (RINGLE; SILVA; BIDO, 2014, p. 68). O critério utilizado para avaliar o modelo refere-se a valores maiores que zero. Nota-se que todos os indicadores de Stone-Geisser $\left(\mathrm{Q}^{2}\right)$ apresentam valores maiores que 0 , ou seja, há qualidade da predição do modelo ajustado ((HAIR Jr. et al., 2014; RINGLE; SILVA; BIDO, 2014).

O tamanho do efeito $\left(\mathrm{f}^{2}\right)$ "é obtido da inclusão e exclusão de construtos do modelo (um a um). Avalia-se quanto cada construto é útil para o ajuste do modelo" (RINGLE; SILVA; BIDO, 2014, p. 68). Valores de $0,02,0,15$ e 0,35 , respectivamente, representam pequeno, médio e grande efeito. Com relação ao tamanho do efeito $\left(\mathrm{f}^{2}\right)$, ou indicador de Cohen, nota-se que os construtos: apresentação $(0,585)$, pessoal e serviços $(0,521)$, preço $(0,519)$, promoção $(0,479)$ e mix de produtos $(0,413)$ representam, respectivamente, grande efeito para o ajuste do modelo (HAIR Jr. et al., 2014; RINGLE; SILVA; BIDO, 2014), enquanto que o construto ponto e localização $(0,201)$ representa médio efeito para o ajuste do modelo (HAIR Jr. et al., 2014; RINGLE; SILVA; BIDO, 2014).

Os relacionamentos entre as variáveis latentes no modelo estrutural são representados pelos coeficientes de caminho (HAIR Jr. et al., 2014). A Tabela 7 demonstra os coeficientes de caminho, que são interpretados como os betas $(\beta)$ das regressões lineares simples (RINGLE; SILVA; BIDO, 2014).

Tabela 6 Coeficientes de caminho consumidor cluster comercial espontâneo

\begin{tabular}{l|r|r|r|r|r|r}
\hline & Apresentação & $\begin{array}{c}\text { Mix de } \\
\text { Produtos }\end{array}$ & $\begin{array}{c}\text { Pessoal e } \\
\text { Serviços }\end{array}$ & $\begin{array}{c}\text { Ponto e } \\
\text { Localização }\end{array}$ & Preço & Promoção \\
\hline $\begin{array}{l}\text { Intenção de } \\
\text { Compra }\end{array}$ & 0,970 & 0,828 & 0,865 & 0,772 & 0,760 & 0,672 \\
\hline
\end{tabular}

Fonte: Dados extraídos do software Smart PLS.

A interpretação da Tabela 6 permite identificar a importância de cada construto ou variável latente em relação ao construto intenção de compra. Nota-se que o construto apresentação é considerado o mais importante com uma carga fatorial de 0,970, semelhante ao encontrado nos polos comerciais de São Miguel Paulista, Vila Nova Cachoeirinha e Capão Redondo (PARENTE et al., 2012) e ocupa uma posição intermediária nos clusters comerciais da Rua Santa Ifigênia e da Rua São Caetano (TELLES et al., 2013). O construto pessoal e serviços, com carga fatorial de 0,865 , foi o segundo mais importante, idêntico ao encontrado no cluster comerciais da Rua São Caetano (TELLES et al., 2013). Resultado contrário foi encontrado no aglomerado varejista venezuelano (SILVA et al., 2014), e na Rua Santa Ifigênia (TELLES et al., 2013). O mix de produtos, com carga fatorial de 0,828 , encontra-se em posição intermediária, igual ao encontrado nos clusters comerciais da Rua Santa Ifigênia e Rua São Caetano (TELLES et al. (2013), e ocupa posição de maior importância no aglomerado varejista venezuelano (SILVA et al., 2014). Também em posição intermediária $\mathrm{o}$ ponto $\mathrm{e}$ localização, com carga fatorial de 0,772, difere dos clusters comerciais da Rua Santa Ifigênia e Rua São Caetano (TELLES et al.,2013), e no aglomerado varejista venezuelano (SILVA et al., 2014) ocupa a primeira posição. Como fatores de menor importância o preço, com carga fatorial de 0,760 , semelhante ao observado no cluster da Rua São Caetano e de grande importância no cluster da Rua Santa Ifigênia (TELLES et al., 2013), no aglomerado venezuelano ocupa posição intermediária (SILVA et al., 2014); a promoção como menos importante, com carga fatorial de 0,672 , tem posição 
contrária à observada nos clusters da Rua Santa Ifigênia e Rua São Caetano (TELLES et al., 2013) os quais encontram-se como mais importantes e no aglomerado venezuelano está em uma posição mais intermediária (SILVA et al., 2014).

Depreende-se que a ambientação da loja representada, pela apresentação, bem como o atendimento prestado e os serviços oferecidos nos clusters comerciais de automóveis chamam mais a atenção dos consumidores do que preço e promoção, provavelmente por ser o tipo de produto que o consumidor necessita de mais informações para a compra, o que ocorre em um ambiente que deve ser mais agradável. $\mathrm{O}$ fato do mix de produtos encontrar-se em posição intermediária pode estar relacionado a algumas características padronizadas como itens de segurança, cores e modelos de automóveis, que fazem com que o consumidor não as perceba como importante, semelhante ao observado nos eletrônicos do cluster da Rua Santa Ifigênia. Quanto ao ponto e localização não estarem em destaque, sendo uma característica importante para o comércio e sua atratividade (TELLER, 2008; PE'ER; KEIL, 2013; FARIA; SIQUEIRA; CARVALHO, 2013), pode estar relacionado ao fato que o consumidor não se preocupa com a distância ou localização a percorrer. $\mathrm{O}$ preço e a promoção destacam-se por estarem em posição de menor importância, pode ser que isso ocorra devido ao consumidor dispor de grande variedade de lojas para comparação desses itens.

\subsubsection{Varejistas dos clusters comerciais espontâneos}

Inicia-se a análise da validade convergente dos construtos (AVE), para tanto, utiliza-se como critério valores de AVE maiores que 0,50 (PREARO, 2013; RINGLE; SILVA; BIDO, 2014). Como pode ser notado na Tabela 7 todos os valores atendem a esse critério. A seguir, analisa-se a consistência interna representada pela confiabilidade composta

Tabela 7 Valores da validade convergente (AVE)
\begin{tabular}{l|r|r|r}
\hline & AVE & $\begin{array}{r}\text { Composite } \\
\text { Reliability }\end{array}$ & \\
\hline Apresentação & 0,635 & 0,972 & \\
\hline Intenção de Venda & 0,508 & 0,977 & \\
\hline Mix de Produtos & 0,726 & 0,888 & \\
\hline Pessoal e Serviços & 0,604 & 0,914 & \\
\hline Ponto e Localização & 0,699 & 0,874 & \\
\hline Preço & 0,717 & 0,910 & \\
\hline Promoção & 0,668 & 0,909 & \\
\hline
\end{tabular}

Fonte: Dados extraídos do software SmartPLS.

A observação da confiabilidade composta demonstra que todos os construtos apresentam valores maiores que 0,70 . Isso significa que os indicadores dos construtos são altamente confiáveis e intercorrelacionados, "indicando que eles todos parecem medir a mesma coisa" (HAIR Jr. et al., 2009, p. 540). A validade discriminante, segundo o critério de Fornell-Larcker, encontra-se na Tabela 8. 
Tabela 8 Validade discriminante - Fornell-Larcker sem V28

\begin{tabular}{l|r|r|l|l|l|r}
\hline & Apresentação & $\begin{array}{l}\text { Mix de } \\
\text { Produtos }\end{array}$ & $\begin{array}{l}\text { Pessoal e } \\
\text { Serviços }\end{array}$ & $\begin{array}{l}\text { Ponto e } \\
\text { Localização }\end{array}$ & Preço & Promoção \\
\hline Apresentação & 0,797 & & & & & \\
\hline Mix de Produtos & 0,710 & 0,852 & & & & \\
\hline $\begin{array}{l}\text { Pessoal e } \\
\text { Serviços }\end{array}$ & 0,779 & 0,672 & 0,845 & & & \\
\hline $\begin{array}{l}\text { Ponto e } \\
\text { Localização }\end{array}$ & 0,735 & 0,677 & 0,655 & 0,836 & & \\
\hline Preço & 0,641 & 0,683 & 0,662 & 0,485 & 0,846 & \\
\hline Promoção & 0,582 & 0,550 & 0,652 & 0,310 & 0,650 & 0,817 \\
\hline
\end{tabular}

Fonte: Dados extraídos do software SmartPLS.

Verifica-se que a diagonal principal indica os valores da variância extraída de cada construto. Nota-se que tais valores são maiores que o quadrado da correlação entre o construto e qualquer outro construto (HENSELER; RINGLE; SINKOVICS, 2009; PREARO, 2013). A validade discriminante diferencia os construtos, ou seja, "itens individuais medidos devem representar somente um construto latente"
(HAIR Jr. et al., 2009, p. 593). Assim, verifica-se a existência de validade discriminante.

A próxima análise verifica os coeficientes de determinação de Pearson $\left(\mathrm{R}^{2}\right)$ que indicam a qualidade do modelo ajustado (RINGLE; SILVA; BIDO, 2014). Esses podem ser notados na Tabela 9 a seguir.

\begin{tabular}{|c|c|}
\hline & $\begin{array}{c}\mathbf{R} \\
\text { Square } \\
\end{array}$ \\
\hline Apresentação & 0,933 \\
\hline Mix de Produtos & 0,650 \\
\hline Pessoal e Serviços & 0,752 \\
\hline Ponto e Localização & 0,581 \\
\hline Preço & 0,591 \\
\hline Promoção & 0,499 \\
\hline
\end{tabular}

Fonte: Dados extraídos do software SmartPLS.

Entende-se, com base nos coeficientes de determinação de Pearson $\left(\mathrm{R}^{2}\right)$, que os indicadores explicam 93,3\% do construto apresentação e $75,2 \%$ do construto pessoal e serviços, considerada uma explicação substancial. Do mesmo modo, os indicadores explicam, respectivamente, $65,0 \%$ do construto mix de produtos, $59,1 \%$ do construto preço, $58,1 \%$ do construto ponto e localização, e $49,9 \%$ do construto promoção, todos esses considerados como explicação moderada (CHIN, 1998 apud PREARO, 2013).
O teste de significância das relações, executado por bootstrapping, verifica a significância estatística de cada coeficiente estrutural por meio do teste t de Student. Todos os valores do teste $t$ das relações entre os construtos com seus respectivos indicadores estão acima de 1,96. Do mesmo modo, verifica-se que os valores do teste $\mathrm{t}$ entre os referidos construtos e o construto intenção de venda também são superiores a 1,96 (HAIR Jr. et al., 2009; PREARO, 2013; RINGLE; SILVA; BIDO, 2014).

Os valores de $\mathrm{p}$ foram inferiores a 0,05 , o que permite aceitar as hipóteses 
testadas, o que significa que as cargas fatoriais e os coeficientes de regressão são significantes (RINGLE; SILVA; BIDO,
2014). A Tabela 10 demonstra os valores de p e a Figura 7 as hipóteses testadas.

Tabela $10 \mathrm{p}$ values

\begin{tabular}{l|c}
\hline & $\begin{array}{c}\mathbf{p} \\
\text { values }\end{array}$ \\
\hline INTENÇÃO DE VENDA -> APRESENTAÇÃO & $<0,05$ \\
\hline INTENÇÃO DE VENDA -> MIX DE PRODUTOS & $<0,05$ \\
\hline INTENÇÃO DE VENDA -> PESSOAL E SERVIÇOS & $<0,05$ \\
\hline INTENÇÃO DE VENDA -> PONTO E LOCALIZAÇÃO & $<0,05$ \\
\hline INTENÇÃO DE VENDA -> PREÇO & $<0,05$ \\
\hline INTENÇÃO DE VENDA -> PROMOÇÃO & $<0,05$ \\
\hline
\end{tabular}

Fonte: Dados extraídos do software Smart PLS.

Figura 7 - Hipóteses varejistas

\begin{tabular}{|l|l|}
\hline Hipóteses & \\
\hline $\begin{array}{l}\text { H7: o mix de produto provoca um resultado positivo na } \\
\text { intenção de venda nos clusters comerciais espontâneos de } \\
\text { automóveis }\end{array}$ & Confirmada \\
\hline $\begin{array}{l}\text { H8: a apresentação provoca um resultado positivo na intenção } \\
\text { de venda nos clusters comerciais espontâneos de automóveis }\end{array}$ & Confirmada \\
\hline $\begin{array}{l}\text { H9: o preço provoca um resultado positivo na intenção de } \\
\text { venda nos clusters comerciais espontâneos de automóveis }\end{array}$ & Confirmada \\
\hline $\begin{array}{l}\text { H10: a promoção provoca um resultado positivo na intenção } \\
\text { de venda nos clusters comerciais espontâneos de automóveis }\end{array}$ & Confirmada \\
\hline $\begin{array}{l}\text { H11: pessoal e serviços provocam um resultado positivo na } \\
\text { intenção de venda nos clusters comerciais espontâneos de } \\
\text { automóveis }\end{array}$ & Confirmada \\
\hline $\begin{array}{l}\text { H12: o ponto e localização provocam um resultado positivo na } \\
\text { intenção de venda nos clusters comerciais espontâneos de } \\
\text { automóveis }\end{array}$ & Confirmada \\
\hline
\end{tabular}

Fonte: elaborado pelos autores.

A qualidade do ajuste do modelo, representado pela relevância ou validade preditiva $\left(\mathrm{Q}^{2}\right)$ ou indicador de Stone-
Geisser e tamanho do efeito $\left(\mathrm{f}^{2}\right)$ ou indicador de Cohen (RINGLE; SILVA; BIDO, 2014) encontram-se na Tabela 11.

Tabela 11 Indicadores de Stone-Geisser e Cohen

\begin{tabular}{l|c|c}
\hline \multicolumn{1}{c|}{ Construtos } & $\mathbf{Q}^{\mathbf{2}}$ & $\mathbf{f}^{\mathbf{2}}$ \\
\hline Pessoal e Serviços & 0,521 & 0,520 \\
\hline Mix de Produtos & 0,463 & 0,436 \\
\hline Ponto e Localização & 0,389 & 0,382 \\
\hline Apresentação & 0,580 & 0,585 \\
\hline Promoção & 0,299 & 0,482 \\
\hline Preço & 0,412 & 0,519 \\
\hline
\end{tabular}

Fonte: Dados extraídos do software SmartPLS. 
Todos os indicadores da validade preditiva ou indicadores de Stone-Geisser $\left(\mathrm{Q}^{2}\right)$ apresentam valores maiores que 0 , ou seja, há qualidade da predição do modelo ajustado (HAIR Jr. et al., 2014; RINGLE; SILVA; BIDO, 2014).

Com relação ao tamanho do efeito $\left(\mathrm{f}^{2}\right)$ ou indicador de Cohen, nota-se que todos os construtos apresentam grande efeito para o ajuste do modelo ao apresentar valores maiores que 0,35 . Os coeficientes de caminho descrevem os relacionamentos entre as variáveis latentes no modelo estrutural (HAIR Jr. et al., 2014; RINGLE; SILVA; BIDO, 2014), conforme Tabela 12.

Tabela 12 Coeficientes de caminho varejista cluster comercial espontâneo

\begin{tabular}{l|r|r|l|r|r|r}
\hline & Apresentação & $\begin{array}{l}\text { Mix de } \\
\text { Produtos }\end{array}$ & $\begin{array}{l}\text { Pessoal e } \\
\text { serviços }\end{array}$ & $\begin{array}{l}\text { Ponto e } \\
\text { Localização }\end{array}$ & Promoção & Preço \\
\hline $\begin{array}{l}\text { Intenção de } \\
\text { Venda }\end{array}$ & 0,966 & 0,807 & 0,867 & 0,762 & 0,707 & 0,769 \\
\hline
\end{tabular}

Fonte: Dados extraídos do software SmartPLS.

A Tabela 12 permite identificar a importância de cada construto ou variável latente em relação ao construto intenção de venda. Notase que o construto apresentação é considerado o mais importante com uma carga fatorial de 0,966, seguido por pessoal e serviços com carga fatorial de 0,867 , mix de produtos com carga fatorial de 0,807 , preço com carga fatorial de 0,769 , ponto e localização com carga fatorial de 0,762 e promoção com carga fatorial de 0,707 .

Diversos autores estudaram a importância dos fatores ambientais no varejo, apresentação, como preditores das respostas dos consumidores (BAKER; GREWAL; PARASURAMAN, 1994; TOMAZELLI; ESPARTEL; UGALDE, 2010; BRITO; PAULA, 2012). Durante a visita, o ambiente físico (tangível) é importante para o consumidor, pois ajuda-o a formar as impressões sobre o lugar em que se encontra. Com relação ao fator pessoal e serviços destaca-se o trabalho de Grande (2004), o qual relata o investimento das montadoras de automóveis no atendimento ao consumidor nas concessionárias, bem como o estudo de Comiotto et al. (2014), sobre as ações de pósvenda em concessionárias de automóveis e, o trabalho de Gurgel, Nóbrega e Leone (2012), sobre as práticas de recuperação de serviços em concessionárias de automóveis. Quanto ao mix de produtos o estudo de Briesch,
Chintagunta e Fox (2009) identificou que a variedade de produtos no varejo é mais importante que o preço na atratividade, assim como em uma concessionária de automóveis de João Pessoa (LINS; NUNES; LIMA, 2009), conforme constatado nesta pesquisa; embora o preço tenha sido considerado importante em concessionárias de automóveis novos (SAMPAIO et al., 2004). Destaca-se que o fator ponto e localização se encontra na penúltima posição, indicando a pequena importância desse na intenção de venda. Esse fato diverge do que consta da literatura, em que o ponto e a localização são tão importantes que podem influenciar a atratividade do varejo (PARENTE, 2000; ORUC, 2005; PAULA, 2008; LINS; NUNES; LIMA, 2009; FARIA; SIQUEIRA; CARVALHO, 2013; ALIPOUR-HAFEZI et al., 2013). Em clusters comerciais espontâneos, os varejistas consideraram a localização como fator importantíssimo (REIMERS e CLULOW, 2004). O resultado encontrado na promoção diverge do obtido em uma concessionária de veículos em João Pessoa, o qual destaca-se como um fator importante (LINS, NUNES e LIMA, 2009). A figura 8, a seguir, apresenta os fatores convergentes e divergentes. Pode-se inferir que os varejistas pesquisados conhecem bem os fatores de atração valorizados pelos consumidores. 
Figura 8 - Convergência dos fatores entre consumidores e varejistas nos clusters comerciais espontâneos

CONSUMIDORES

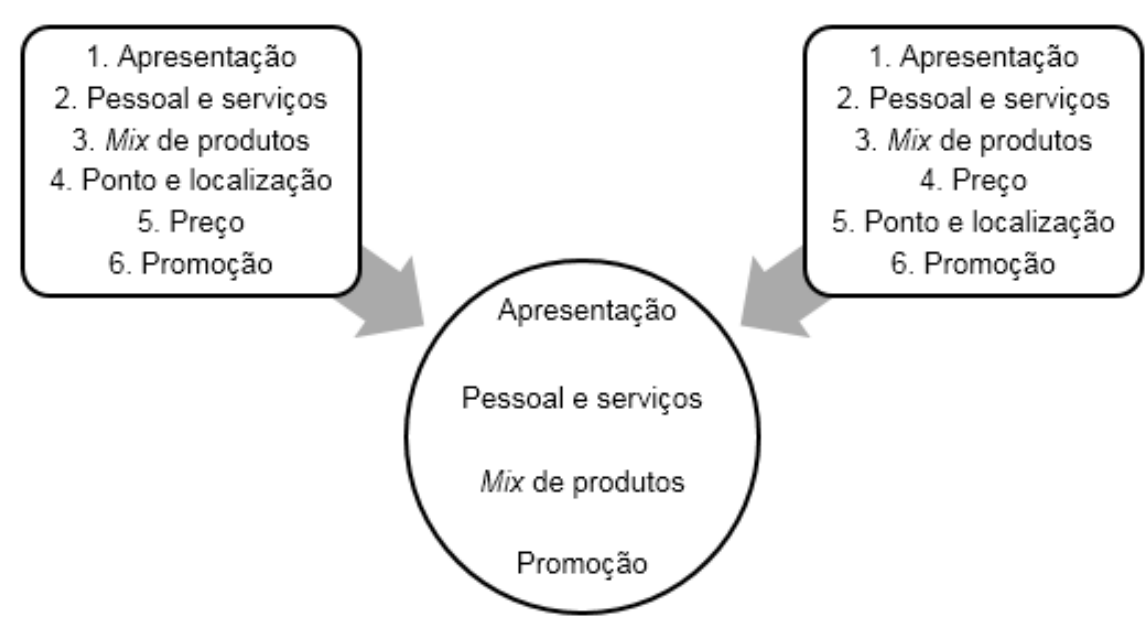

Fonte: dados da pesquisa

\subsection{Atratividade em clusters comerciais}

Como se deseja saber se há relação entre intenção de compra e intenção de venda e se esta é significativa e positiva, caracterizando assim a atratividade em clusters comerciais espontâneos de automóveis, toma-se como hipótese nula:

$H_{0}$ : não há relação entre intenção de compra e intenção de venda.

\section{Tabela 13 Correlação de Pearson cluster comercial espontâneo Correlações}

\begin{tabular}{l|l|r|r}
\hline \multicolumn{2}{c|}{} & \multicolumn{1}{c|}{ Compra } & \multicolumn{1}{c}{ Venda } \\
\hline \multirow{4}{*}{ Compra } & Correlação de Pearson & 1 &, $999^{* *}$ \\
\cline { 2 - 4 } & Sig. (2 extremidades) & &, 000 \\
\cline { 2 - 4 } & N & 104 & 104 \\
\hline \multirow{4}{*}{ Venda } & Correlação de Pearson &, $999^{* *}$ & 1 \\
\cline { 2 - 4 } & Sig. (2 extremidades) &, 000 & \\
\cline { 2 - 4 } & $\mathrm{N}$ & 104 & 104 \\
\hline
\end{tabular}

**. A correlação é significativa no nível 0,01 (2 extremidades).

Fonte: dados extraídos do software SPSS. 
Tabela 14 Correlação de Spearman cluster comercial espontâneo

\begin{tabular}{|c|c|c|c|c|}
\hline \multicolumn{5}{|c|}{ Correlações } \\
\hline & & & Compra & Venda \\
\hline \multirow{6}{*}{ Tau_b de Kendall } & \multirow{3}{*}{ Compra } & Correlações de coeficiente & 1,000 & $975^{\circ+}$ \\
\hline & & Sig. (2 extremidades) & &, 000 \\
\hline & & $\mathrm{N}$ & 104 & 104 \\
\hline & \multirow{3}{*}{ Venda } & Correlações de coeficiente & $975^{\circ *}$ & 1,000 \\
\hline & & \begin{tabular}{|l|} 
Sig. (2 extremidades) \\
\end{tabular} &, 000 & \\
\hline & & $\mathrm{N}$ & 104 & 104 \\
\hline \multirow{6}{*}{ Rô de Spearman } & \multirow{3}{*}{ Compra } & Correlações de coefíciente & 1,000 & $998^{*+}$ \\
\hline & & Sig. (2 extremidades) & &, 000 \\
\hline & & $\mathrm{N}$ & 104 & 104 \\
\hline & \multirow{3}{*}{ Venda } & Correlações de coeficiente &, $998^{*+}$ & 1,000 \\
\hline & & Sig. (2 extremidades) &, 000 & \\
\hline & & $\mathrm{N}$ & 104 & 104 \\
\hline
\end{tabular}

Fonte: dados extraídos do software SPSS.

Os dados das Tabelas 13 e 14 demonstram que a correlação de Pearson entre intenção de compra e intenção de venda é de 0,999 com um nível de significância de 0,01 . Quanto maior o coeficiente de correlação de Pearson, mais forte é a ligação entre variáveis. Coeficiente de correlação entre 0,91 a 1,00 é considerado muito forte, o que representa alta probabilidade de haver uma relação significativa entre as duas variáveis (HAIR Jr. et al., 2005). No caso em estudo, o coeficiente de correlação aproxima-se de 1,0 , o que indica que há uma relação muito forte entre intenção de compra e intenção de venda, caracterizando-se, assim, a atratividade nos clusters comerciais espontâneos pesquisados e se rejeita a hipótese nula.

A correlação de Spearman é considerada como uma estatística mais conservadora (HAIR Jr. et al., 2005), mas também confirmou a correlação positiva $(0,998)$ e a sua força. Dessa forma, encontrou-se uma força que une duas partes e promove, voluntariamente, uma relação (MORTENSEN, 2012), na qual consumidores e varejistas são atraídos por interesses mútuos (ELLEGAARD; RITTER, 2007), o que gera interação entre as partes (HARRIS; O'MALLEY; PATTERSON, 2003; ELLEGAARD; RITTER, 2007).

\section{CONCLUSÃO}

Nesta pesquisa, o consumidor elegeu os fatores que mais se destacaram em sua intenção de compra, conforme suas necessidades ou seus desejos, e o varejista considerou quais os atributos mais valorizados pelo consumidor em sua intenção de venda. Assim, buscou-se entender a atratividade como a convergência entre essas duas intenções.

Uma das limitações encontradas neste estudo refere-se ao fato da amostra não ter sido probabilística, assim, os resultados não podem ser projetados para a população. A utilização de uma amostra probabilística permitiria uma visão mais ampla sobre a atratividade do ponto de vista de consumidores e varejistas.

O reduzido número de estudos nacionais e internacionais sobre o tema atratividade em clusters comerciais espontâneos, considerando o ponto de vista dos consumidores e varejistas simultaneamente, também foi uma limitação. Os resultados encontrados não puderam ser comparados com outros estudos, o que poderia demonstrar se há diferenças significativas na atratividade em diferentes cidades e distintos perfis de consumidores e varejistas. 
Para futuras pesquisas, propõe-se o estudo da atratividade em clusters comerciais espontâneos em outras cidades para observar se os resultados seriam os mesmos. Pode-se também testar o modelo proposto em outros clusters comerciais espontâneos, como móveis e vestuário. Sugere-se, também, verificar se outras variáveis, tais como renda e grau de escolaridade, afetam a avaliação da atratividade em clusters comerciais espontâneos.

O estudo da atratividade em clusters comerciais representa um campo de estudo a ser ampliado e aprofundado. Se, em momentos em que a economia cresce, atrair consumidores é vantajoso, nos momentos de crise econômica, o estudo da atratividade pode tornar-se uma questão de sobrevivência para os varejistas inseridos em clusters comerciais. Entender os fatores mais valorizados e trabalhar os fatores menos valorizados pelos consumidores pode auxiliar a superar as crises pelas quais a economia passa.

Finalizando, pode-se inferir que a observância da atratividade nos clusters comerciais pode se mostrar uma vantagem competitiva para os varejistas, ali situados, tornando a competição mais difícil para as lojas isoladas e os clusters concorrentes.

\section{Referências}

AGUIAR, H.; PEREIRA, C.; DONAIRE, D. Polo varejista do bom retiro: cluster de negócios da moda. In: XVII SIMPÓSIO DE ADMINISTRAÇÃO DA PRODUÇÃO, LOGÍSTICA E OPERAÇÕES INTERNACIONAIS (SIMPOI), n. XVII, 2014, São Paulo.

AKROUSH, M. The 7Ps classification of the services marketing mix revisited: na empirical assessment of their generalisability, applicability and effect on performance - evidence from Jordan's organizations. Jourdan Journal of Business Administration, v. 7, n. 1, p. 116$147,2011$.

ALIPOUR-HAFEZI et al. Using 4P Marketing Model in Academic Libraries: An Experience. International Journal of Information Science and Management, v3, n. 2, p. 45-58, 2013. ARANHA, F.; FIGOLI, S. Geomarketing: memórias de viagem. 2001 São Paulo, dez. 2001. Disponível em http://www.academia.edu/562531/GeoMarketing_Mem\%C3\%B3rias_de_viagem. Acesso em: 17 nov. 2014.

BAKER, J.; GREWAL, D.; PARASURAMAN, A. The influence of store environment on quality inferences and store image. Journal of the Academy of Marketing Science, v. 22,n. 4, p. 328-339, 1994.

BANERJE, N. A study on the attractiveness dimensions of shopping malls - an indian perspective. International Journal of Business and Social Science,v.3,n. 2, p. 102-111, 2012.

BERMAN, B.; EVANS, J. Retail management: a strategic approach. New Jersey: Prentice Hall, 1998.

BLACKWELL, R.; MINIARD, P.; ENGEL, J. Comportamento do consumidor. São Paulo: Pioneira Thomson Learning, 2005. 
BOLTON, R.; SHANKAR, V. An empirically derived taxonomy of retailer pricing and promotion strategies. Journal of Retailing, v. 79, p. 213-224, 2003.

BOYD, H. Administração de marketing. São Paulo: Saraiva, 1978.

BRIESCH, R.; CHINTAGUNTA, P.; FOX, E. How Does Assortment Affect Grocery Store Choice? Journal of Marketing Research, v. 46, n. 2, p. 176-189, 2009.

BRITTO, M.; PAULA, S. Atmosfera da loja: a importância do ambiente dos provadores de roupas no varejo de vestuário. In Encontro de Marketing da ANPAD. n. V, 2012, Curitiba.

BUENO, F. Grande dicionário etimológico-prosódico da língua portuguesa. São Paulo: Brasília, 1974.

BURT, S.; CARRALERO-ENCINAS, J. On the relationship between store image, store satisfaction and store loyalty. European Journal of Marketing, v. 32, n. 5/6, p. 499-513, 2000 .

CAMBRIDGE DICTIONARIES ON-LINE. Disponível em http://dictionary.cambridge.org/dictionary/british/attraction. Acesso em: 31 ago. 2014.

CAMPOS, D.; LUNDBERG, F.. Satisfação e atratividade: como o público jovem avalia os shopping centers. Revista Eletrônica do Mestrado em Administração da Universidade Potiguar-RAUnP, v.5, n.2, p. 79-97, 2013.

CHEBAT, J.; SIRGY, M.;GRZESKOWIAK, A. How can shopping mall management best capture mall image? Journal of Business Research, n. 63, p. 735-740, 2010.

CHUNG, W.; KALNINS, A. Agglomeration effects and performance: a test of the Texas loadging industry. Strategic Management Journal, n.22, p. 969-988, 2001.

COMIOTTO, F. et al. Comprei meu carro, o que vem depois? Análise da percepção e da importância atribuídas por clientes em serviços de pós-venda. Revista Brasileira de Marketing, v. 13, n. 6, p. 80-93, 2014.

DATTA, S.; SUDHIR, K. The Agglomeration-Differentiation Tradeoff in Spatial Location choice. 2011. Manuscript. Yale School of Management. Disponível em http://faculty.som.yale.edu/ksudhir/workingpapers/Agglomeration\%20Differentiation\%20Tra deoff-June.pdf. .Acesso em: 21 abr. 2013.

DHAR, S.; HOCH, S.; KUMAR, N. Effective category management depends on the role of the category. Journal of Retailing, v. 77, p. 165-184, 2001.

DONAIRE, D. et al. Competitividade de clusters comerciais: estudo sobre uma aglomeração de pequenas lojas de veículos no município de São Paulo. Revista da Micro e Pequena Empresa. Campo Limpo Paulista, n. 3, v. 7, p. 64-78, 2013.

EL-ADLY, M. Shopping malls attractiveness: a segmentation approach. International Journal of Retail \& Distribution Management, v.35, n. 11, p. 936-950, 2007. 
ELIAS, D.; CAMARGO JÚNIOR, A. Segmentação, localização e área de influência de lojas no varejo. In Encontro da ANPAD, n. 32, 2008, Rio de Janeiro.

ELLEGAARD, C.; RITTER, T. Attractiveness in business markets: conceptualization and propositions. 23rd IMP-conference in Manchester, UK, 2007.

FARIA, M.; SIQUEIRA, R.; CARVALHO, J. Diversidade no varejo: impactos de acessibilidade e inclusão na intenção de compra. Revista Brasileira de Marketing, v. 12, n. 3, p.231-259, jul.-set. 2013.

FEIJÓ, F.; BOTELHO, D. Efeitos dos fatores de merchandising nas vendas do varejo.

Revista de Administração de Empresas, v. 52, n. 6, p. 628-642, 2012.

FERREIRA, A. Concorrência é a 'alma' das ruas de comércio especializado, dizem consultores e lojistas. Disponível em http://economia.uol.com.br/ultimasnoticias/redacao/2012/02/29/forte-concorrencia-e-a-alma-das-ruas-de-comercioespecializado.jhtm. Acesso em: 18 nov. 2014.

FERREIRA, H.; PATAH, L. Efeitos primários supra empresariais: um estudo exploratório em um aglomerado de empresas que atuam no ramo de importados. Revista Eletrônica Gestão \& Sociedade, v.13, n.32, p. 2287-2306, 2018.

FITTIPALDI, M. et al. O uso da análise de redes sociais para identificar a coopetição em um cluster comercial planejado. In Encontro Internacional sobre Gestão Empresarial e Meio Ambiente - ENGEMA. n. 16, 2013, São Paulo.

GASPAR, M. et al. Análise das vantagens competitivas de um cluster comercial varejista: estudo de caso na Rua Jurubatuba. In Seminários em Administração - SEMEAD. n. 17, 2014, São Paulo.

GRANDE, M. A distribuição de automóveis novos em mudança? Estudo a partir de survey e pesquisa qualitativa em concessionárias. [Tese]. São Paulo. Universidade de São Paulo Escola Politécnica; 2004.

GRÖNROOS, C. Marketing: gerenciamento e serviços. 5. ed. Rio de Janeiro: Campus, 2000.

GURGEL, J.; NÓBREGA, K.; LEONE, R. Recuperação de serviços: um estudo com clientes de concessionárias de veículos. In SIMPOI. n. XV, 2012, São Paulo.

HAIR Jr., J. et al. Fundamentos de métodos de pesquisa em administração. Porto Alegre: Bookman, 2005.

HAIR Jr., J. et al. Análise multivariada de dados. 6. ed. Porto Alegre: Bookman, 2009.

HAIR Jr. J. et al. A primer on partial least squares structural equation modeling (PLSSEM). Sage, 2014.

HARRIS, L.; O'MALLEY, L.; PATTERSON, M. Professional interaction: Exploring the concept of attraction. Marketing Theory, v. 3, n.1, p. 9-36, 2003. 
HEINZ, D.; COSTA, J.; PEREIRA, E. Composto de marketing em redes de compras: estudo comparativo das percepções de administradores e associados em uma rede de supermercados. READ- Revista Eletrônica de Administração, v. 78, n.2, p. 529-570, 2014.

HENSELER, J.; RINGLE, C.; SINKOVICS, R. The use of partial least squares path modeling in international marketing. Advances in International Marketing.v. 20, p. 277-319, 2009. HOWELL, R.; ROGERS, J. Research into shopping mall choice behavior. Advances in Consumer Research, v.8, p.671-676, 1981.

IBRAHIM, M.; WEE, C. The impact of entertainment in shopping center experience: evidence from Singapore. Journal of Real Estate Portfolio Management, v. 8, n. 3, 2002.

ILLANES, M.; IKEDA, A. O estímulo olfativo como ferramenta de marketing no varejo. In SEMEAD. 12, 2009, São Paulo.

KHARE, A. Mall shopping behavior of indian small town consumers. Journal of Retailing and Consumer Services, v.18, p. 110-118, 2011.

KUKAR-KINNEY, M; RIDGWAY, N.; MONROE, K. The role of price in the behavior and purchase decisions of compulsive buyers. Journal of Retailing, v. 88, n. 1, p.63-71, 2012.

LAROCHE, M. et al. Incorporating service quality into consumer mall shopping decision making: a comparison between English and French Canadian consumers. Journal of Services Marketing, v. 19, n. 3, p. 157-163, 2005.

LAZAROTTI, J. et al. Shopping de luxo e lojas populares do Bom Retiro: a influência da imagem da loja na decisão de compra de vestuário feminino. Jovens Pesquisadores, v. 4, n.1, p. 1-15, 2007.

LEVY, M.; WEITZ, B. Administração de varejo. São Paulo: Atlas, 2000.

LIMA, L. Tipologia motivacional de consumo de adolescentes em shopping centers. READ Revista Eletrônica de Administração, v. 14, n.1, p. 1-18, 2008.

LINS, S.; NUNES, A.; LIMA, W. Qualidade de Serviços: Um Estudo de Caso no Setor de Carros Seminovos. Revista de Administração da UNIMEP, v. 7, n.2, p. 1-24, 2009

LUNDBERG, F.; CAMPOS, D.; SOUZA, T. Atratividade de shopping centers: uma abordagem com o público jovem. In: SIMPOI. Anais. São Paulo: FGV, 2012. p. 1-16.

MALHOTRA, N. Pesquisa de Marketing: uma orientação aplicada. Porto Alegre: Bookman, 2012.

MARIETO, M.; SANCHES, C. Estratégia como prática: um estudo das práticas da ação estratégica no cluster de lojas comerciais da rua das noivas em São Paulo. Revista Pensamento Contemporâneo em Administração, v. 7, n. 13, p. 38-58, 2013.

MARQUES JUNIOR, V.; MARTINS, I.; MERLO, E. Shopping centers, uma relação entre os atributos de escolha pelos consumidores versus os atributos valorizados pelos gerentes.

Gestão e Sociedade, v. 3, n.6, p. 360-388, 2009. 
MATTAR, F. Administração de varejo. Rio de Janeiro: Elsevier, 2011.

MELO JUNIOR, Y. Identificação e hierarquização dos atributos da qualidade de shopping centers de mix temático com ênfase em produtos de alta comparação. [Dissertação]. São Paulo. Universidade de São Paulo - Escola Politécnica; 2005.

MICHON, R. et al. The influence of mall environment on female fashion shoppers' value and behavior. Journal of Fashion Marketing and Management, v. 12, n. 4, p. 446-456, 2008.

MORTENSEN, M. Understanding attractiveness in business relationships - A complete literature review. Industrial Marketing Managemen,. v. 41, n.8, p. 1206-1218, 2012.

NELSON, R. The selection of retail location. F. W. Dodge Corporation: New York, 1958. OPPEWAL, H.; HOLYOAKE, B. Bundling and retail agglomeration effects on shopping behavior. Journal of Retailing and Consumer Services, v.11, n.2, p.61-74, 2004.

ORUC, N. Retail gravity model analysis of store choice behavior of hypermarket shoppers in Sarajevo. European Retail Digest, v. 47, p. 31-34, 2005.

PARENTE, J. Varejo no Brasil: gestão e estratégia. São Paulo: Atlas, 2000.

PARENTE, J. et al. Polos varejistas de rua ou shopping centers? Comparando as preferências da baixa renda. BBR Brazilian Business Review. Edição especial, Vitória, p. 162-189, 2012.

PARENTE, J.; BARKI, E.; KATO, H. Estratégias de Marketing para o Varejo na Baixa Renda. In: Encontro da ANPAD, n. 31, 2007, Rio de Janeiro.

PARSONS, A. Assessing the effectiveness of shopping mall promotions: customer analysis. International Journal of Retail \& Distribution Management, v. 31, n. 2, p. 74-79, 2003.

PAULA, V. Estratégia de marcas no varejo de alimentos: concepção e gestão de marcas próprias na Inglaterra e no Brasil. [Tese]. São Carlos: Universidade Federal de São Carlos. Faculdade de Engenharia de Produção: 2008.

PE'ER, A.; KEIL, T. Are all startups affected similarly by clusters? Agglomeration, competition, firm heterogeneity, and survival. Journal of Business Venturing, v.28, n.3, p. 354-372. 2013.

PIMENTA, R.; BRANDÃO, M.; SILVA, L. Efeitos da percepção de crowding e apresentação de preço: um estudo experimental. In Encontro de Marketing da ANPAD. $\mathrm{n}$. VI, 2014, Gramado.

PORRAL, C.; DOPICO, D. Estudio exploratorio sobre los factores de atracción de centros comerciales: uma aproximación al consumidor español. Ciência Ergo, v.20, n.2, p. 107-120, jul.- oct. 2013.

PREARO, L. Os serviços públicos e o bem-estar subjetivo da população: uma modelagem multigrupos baseada em mínimos quadrados parciais [Tese]. São Paulo: Universidade de São Paulo. Faculdade de Economia, Administração e Contabilidade. Departamento de Administração; 2013. 
REIMERS, V.; CLULOW, V. Retail concentration: a comparison of spatial convenience in shopping strips and shopping centres. Journal of Retailing and Consumer Services. v. 11, n.4. p. 207-221, 2004.

RIBEIRO, F. et al. Os aromas da moda: investigando o uso do marketing sensorial olfativo no varejo de vestuário de belo horizonte. Estudo \& Debate, v. 21, n.1, p. 217-238, 2014.

RINGLE, C.; SILVA, D.; BIDO, D. Modelagem de equações estruturais com utilização do SMARTPLS. Revista Brasileira de Marketing, v. 13, n. 2, p. 54-71, 2014.

ROODERKERK, R.; van HEERDE, H.; BIJMOLT, T. Optimizing Retail Assortments. Marketing Science, v. 32, n. 5, p. 699-715, 2013.

SAMPAIO, D. et al. Um estudo comparativo sobre o comportamento do consumidor de automóveis novos. In Seminários em Administração, n. VII, 2004, São Paulo.

SARMENTO, R. Coopetição em Aglomerações Comerciais Planejadas e Não Planejadas. [Tese]. São Caetano do Sul. Universidade de São Caetano do Sul; 2016.

SCHIELE, H.; VELDMAN, J.; HÜTTINGER, L. Customer attractiveness, supplier satisfaction and preferred customer status: review, concept and research agenda. In: IPSERA conference on customer attractiveness, supplier satisfaction and customer value, University of Twente, Enshede, Netherlands, 2010, p. 1-16.

SILVA, R.; SILVEIRA, J. A precificação em um cluster de supermercados. In Seminários em Administração. n. 7, 2004, São Paulo.

SILVA, R. et al. Fatores formadores de atratividade na perspectiva do consumidor brasileiro na aglomeração varejista da fronteira Brasil/Venezuela. In Encontro de Marketing da ANPAD, n. VI, Gramado, 2014.

SILVA, D.; ALMEIDA, E. O marketing mix em franquias de pequeno porte: o caso da franquia de perfumes o boticário. Revista Eletrônica de Ciência Administrativa, v. 2, n. 2, 2003.

SILVEIRA, R.; SINEM, M. Quem te viu, quem te vê: as mudanças do composto mercadológico do varejo de shopping centers da região do Vale do Itajaí/SC durante a sua existência. Revista de Administração UFSM, v.2, n.2, p. 214-234, 2009.

SINGH, H.; SAHAY, V. Determinants of shopping experience. International Journal of Retail \& Distribution Management, v. 40, n. 3, p. 235-248, 2012.

SIQUEIRA, J. et al. Clusters comerciais: uma realidade estratégica no varejo. In: Congresso Latino Americano de Varejo. n. 3, 2010, São Paulo.

SIQUEIRA, J. et al. Competitividade de lojas isoladas e em clusters: um estudo comparativo na cidade de São Paulo. Revista Espacios digital. v. 33, n. 4, p. 2, 2012. 
SIQUEIRA, J. ; LOLLO, R.; TELLES, R. Feira da Flores do CEAGESP: gênese e evolução de um cluster de negócios varejistas. In: Seminários em Administração. n. XVI, São Paulo, 2013.

SIQUEIRA, J. et al. Clusters varejistas: características responsáveis pela atração e afastamento de consumidores. E\&G Economia SIQUEIRA, J. Gestão. v. 15, n. 38, p. 135 $164,2015$.

SPINELLI, P.; GIRALDI, J. Análise teórica e empírica da imagem de loja e da marca própria varejista: implicações estratégicas. Caderno de Pesquisas em Administração, v. 11, n. 4, p. 59-73, 2004.

TELLER, C. Shopping Streets versus Shopping Malls - Determinants of Agglomeration Format Attractiveness from the Consumers' Point of View. The International Review of Retail, Distribution and Consumer Research, v.18, n.4, p. 17-53, 2008.

TELLER, C.; REUTTERER, T. The evolving concept of retail attractiveness: what makes retail agglomerations attractive when customers shop at them? Journal of Retailing and Consumer Services, v.15, n. 3, p. 127-143, 2008.

TELLER, C.; ELMS, J. Managing the attractiveness of evolved and created retail agglomerations formats. Marketing Intelligence \& Planning, v. 28, n. 1, p. 25-45, 2010.

TELLER, C. et al. Place marketing and urban retail agglomerations: an examination of shoppers' place attractiveness perceptions. Macmillan, 2010.

TELLES, R. et al. Clusters comerciais: um estudo sobre concentrações de bares na cidade de São Paulo. Gestão \& Regionalidade, v. 27, n. 81, p. 32-45, 2011

TELLES, R. et al. Atratividade em clusters comerciais: um estudo comparativo de dois clusters da cidade de São Paulo. Gestão \& Regionalidade, v 29, n. 85, jan. - abr. p. 47-62, 2013.

THANG, D.; TAN, B. Linking consumer perception to preference of retail stores: an empirical assessment of the multi-attributes of store image. Journal of Retailing and Consumer Services, v. 10, p. 193-200, 2003.

TOMAZELLI, J.; ESPARTEL, L.; UGALDE M. Ambientação de loja como vantagem competitiva no varejo de confecção. In: Encontro de Marketing da ANPAD, 2010, 4. Florianópolis; 2010, p. 1-17.

VIGARAY, M.; CAMINO, J. Los determinantes de la atracción comercial. Investigaciones Europeas de Dirección y Economía de la Empresa, v. 5, n.2, p. 15-34, 1999. ZACCARELLI, S. Estratégia e sucesso nas empresas. São Paulo: Saraiva, 2003.

VIGARAY, M. et al. Clusters e redes de negócios: uma nova visão para a gestão dos negócios. São Paulo: Atlas, 2008.

YAVAS, U. A multi-attribute approach to understanding shopper segments. International Journal of Retail \& Distribution Management, v. 31, n. 11, p. 541-548, 2003. 
WAGNER, T. Shopping motivation revised: a means-end chain analytical perspective.

International Journal of Retail \& Distribution Management, v. 35, n. 7, p. 569-582, 2007. 